\title{
Removal of COD, BOD and Color from Municipal Solid Waste Leachate using Silica and Iron nano particles - A Comparative Study
}

\author{
Pavithra S. and Shanthakumar S.* \\ Department of Environmental and Water Resources Engineering, School of Civil and Chemical Engineering, VIT University, Vellore- \\ 632014, India
}

Received: 02/07/2016, Accepted: 20/02/2017, Available online: 23/03/2017

*to whom all correspondence should be addressed:

e-mail: shanthakumar.s@vit.ac.in

\begin{abstract}
Application of nano particle in the treatment of municipal solid waste leachate is of recent interest. In this paper, the effectiveness of silica nano particles synthesized from blast furnace slag and iron nano particle synthesized from chemicals was studied for the removal of organic pollutants and color. The synthesized nano particles were characterized using SEM, TEM, EDX and FTIR analysis. Batch experiments were conducted to remove the BOD, COD and color from Aged landfill leachate (ALL) and leachate from the composting yard (CYL). Influencing parameters like $\mathrm{pH}$, contact time, nano particle dosage and Hydrogen peroxide concentration were studied. The maximum removal was achieved at the $\mathrm{pH}$ of 6 for both the nano particle, contact time 90 minutes for silica nano particle and 120 minutes for iron nano particle, silica nano particle dose as $0.4 \mathrm{~g} / 50 \mathrm{ml}$, iron nano particle dose as $0.3 \mathrm{~g} / 50 \mathrm{ml}$ and hydrogen peroxide concentration was found to be $3 \mathrm{M}$ and $4 \mathrm{M}$ for silica and iron nano particles respectively. The removal efficiency in CYL and ALL using silica nano particle was obtained as $87.15 \%, 72.72 \%, 83.15 \%$ and $82.5 \%, 62.5 \%$, $77.34 \%$ for color, BOD and COD respectively. Similarly for iron nano particle, the removal efficiency was found to be $60.3 \%, 65 \%, 67.43 \%$ and $57.06 \%, 57.27 \%, 67 \%$ for the removal of color, $B O D$ and $C O D$ in $C Y L$ and $A L L$, respectively.
\end{abstract}

Keywords: Blast furnace slag, nano particles, batch experiments, leachate treatment, composting yard leachate

\section{Introduction}

Disposal of solid waste in the landfill is one of the common and economically viable waste management approach implemented across the world. In general, most of the metropolitan cities normally perform the landfilling techniques. Thus $90 \%$ of the solid wastes in developing countries like India are disposed in an unempirical approach. The accessibility of land for discarding the generated waste is decreasing day by day (Mor et al., 2006; Siddiqui et al., 2006; Sharholy et al., 2005). Despite cumulative emphasis on unconventional options, solid waste dumping to landfill holds a substantial role in both developed and developing nations. Even though a lot of sophisticated technologies are available, land filling is a very common mode of clearance due to its economic viability. In course of time the solid waste disposed in landfill produces a slimy liquid called "Leachate". The production of leachate and managing the produced leachate is one of the environmental concerns as the produced leachate causes damage to soil and water (both underground and surface water). Unless precautionary procedures are taken, this will lead to a great menace to environment (Baccini et al., 1989; Lopez 2004). Increased concentration of leachate makes the underground water to contaminate very easily (Petruzzelli et al., 2007; Sarvako 2007; Yang 2006). Even though the policy makers have implemented stern rules and regulation, fostering of nonengineered landfills and inefficient collection and treatment system still persist in developing nations (Yemma et al., 1988).

The treatment method chiefly depends on the leachate characteristics. Treatment of leachate is classified into two types namely, physicochemical and biological. In general the biological method is an effective method for the treatment of leachate generated from composting yard due to less non-biodegradable compounds present in it whereas the presence of non-biodegradable compound is high in aged landfill leachate due to which the biological treatment method proves to be ineffective. Thus the physicochemical methods triumph over all this difficulty. For large-scale treatment of wastewater, such as leachate from municipal solid waste landfills, the adsorbents used must be inexpensive and also, should be a waste material obtained from industries or agricultural residue which always be supposed to least processing and it must be plentiful in nature (Esfahani et al., 2012). Quite a good number of reports are presented on the treatment of wastewater and also the pollutant present in the environment using nanotechnology (Sarvako et al., 2008).

Nano particles were preferred for wastewater treatment because of its size, unique network, its structure, higher catalytic ability and also its reactivity (Zang et al., 2007; 
Bailey et al., 1999). In addition, the reason behind the use of nano particle is due to the fact that the reduced surface to volume ratio will increase the absorptive capacity of the nano particles. One of the economical and cost effective treatment techniques is the Fenton process in which the hydrogen peroxide along with ferrous sulphate produces strong hydroxyl radicals. In this paper, the hydrogen peroxide is allowed to react along with the nano particles in order to produce strong hydroxyl radicals. The review of literature reveals that the elements like Cu (Dukkanci et al., 2010), Ce (Xu et al., 2012) Bi (Luo et al., 2010), Mo (Tian et al., 2011), Al (Patra et al., 2013) were incorporated into the nano particles to increase the catalytic ability which results in the decomposition of hydrogen peroxide which gives even more powerful hydroxyl ions. However, Silica nano particle has not been studied for its potential in removing color, BOD and COD. Hence, in this study, an attempt has been made to utilize the waste from foundry unit, Blast furnace slag (BFS) for synthesis of Silica nano particle (SNP). The synthesized SNP was analyzed for its ability to remove color, BOD and COD from municipal solid waste leachate. In addition, the iron nano particle(INP) synthesized from chemical processes has also been studied for its potential in removing color, BOD and COD present in the municipal solid waste leachate.

\section{Materials and methods}

\subsection{Study area and leachate sampling}

Erode, located in the north western part of Tamil Nadu State in India has the city population of 157101(as per 2011 census). In addition to this the floating population was found to be 20,000 . The leachate samples used in this study were collected from a municipal solid waste dumpsite located at Vendipalayam in Erode district $\left(11^{\circ} 34^{\prime} \mathrm{N}\right.$ and $\left.77^{\circ} 72^{\prime} \mathrm{E}\right)$ of Tamil Nadu, India. The dumpsite receives approximately 300 metric tons of waste every day, which excludes hospital waste. Presently, no proper treatment facility is available to treat the leachate in this dump yard. Leachate samples were collected using pre-cleaned polythene bottles and stored in the refrigerator at $4{ }^{\circ} \mathrm{C}$ for further experimentation purpose by following the standard procedure.

\subsection{Synthesis of Silica nano particles}

Raw material used for the synthesis of SNP was granulated blast furnace slag, a waste obtained from a foundry unit. The slag was well grained using a domestic mixer and sieved using 150 microns size sieve. The particles passing through the sieve were collected and stored. The slag and nitric acid was taken in a beaker in the ratio of $1: 4$ and kept for one hour to ensure the completion of reaction. The precipitated silica was washed five times using double distilled water. The same amount of double distilled water as that of nitric acid was added and the mixture was filtered. The extracted silica was oven dried at $200^{\circ} \mathrm{C}$ for one hour. The oven dried silica was stored in an air tight container for further use (Jae Kim et al., 2010).

\subsection{Synthesis of Iron nano particles}

$150 \mathrm{ml}$ of distilled water was mixed with $4.1703 \mathrm{~g}$ of $0.1 \mathrm{M}$ $\mathrm{FeSO}_{4}$ and $150 \mathrm{ml}$ of distilled water was mixed with $3.7224 \mathrm{~g}$ of $0.05 \mathrm{M}$ EDTA. Both the solutions were mixed together. $2.837 \mathrm{~g}$ of $0.75 \mathrm{M} \mathrm{NaBH}_{4}$ was mixed in $100 \mathrm{ml}$ distilled water and added drop wise into the mixture solution. The appearance of black colored particles indicated the formation of nano particles. The black colored particles were washed thrice with ethanol, vacuum filtered, oven dried, and pulverized (Allabaksh et al., 2010).

\subsection{Characterization of leachate}

In this study two different types of leachate were used. The one which was collected from the actual dump site, referred as Aged landfill leachate (ALL). Table 1 represents the composition of solid waste from which the ALL gets generated. In addition to this, the dumpsite also operates an inbuilt composting yard. The leachate generated from this composting yard was referred as Composting yard leachate (CYL). Table 2 represents the composition of solid waste from which the CYL gets generated. All the chemicals used in the study were of analytical grade. The parameters such as $\mathrm{pH}, \mathrm{BOD}, \mathrm{COD}, \mathrm{EC}, \mathrm{TDS}$ and color were determined using the standard methods prescribed by Bureau of Indian Standards (IS: 3025-2009), and heavy metals were determined using the standard methods prescribed by American public health association (APHA, 2012). Table 3 represents the chemical characteristics of ALL and CYL.

Table 1. Composition of solid waste from which the ALL generated (Ramesh et al., 2009)

\begin{tabular}{cc}
\hline Components & Percentage \\
\hline Paper & 3.841 \\
\hline Plastics & 5.833 \\
\hline Organic material & 4.826 \\
\hline Garden trimmings & 60.68 \\
\hline Organic fraction & 1.89 \\
\hline Jute & 2.8 \\
\hline Wood pieces & 5.43 \\
\hline Construction debris & 1.05 \\
\hline Glass & 1.21 \\
\hline Metal & 5.01 \\
\hline Cloth & 1.93 \\
\hline Rubber & 5.56
\end{tabular}

Table 2. Composition of solid waste from which CYL generated

\begin{tabular}{cc}
\hline Components & Percentage \\
\hline Wood \& wood products & 4.76 \\
\hline Pulp, paper \&cardboard & 4.48 \\
\hline Food, food waste, beverages \& tobacco & 74.14 \\
\hline Textiles & 6.82 \\
\hline Garden, yard \& park waste & 4.39 \\
\hline Glass, plastic, metal \& other inert & 5.42 \\
\hline
\end{tabular}

\subsection{Characterization of nano particles}

Fourier Transform Infrared (FT-IR) Spectroscopy (Thermo Nicolet, AVATAR 330) and Scanning Electron Microscopy (SEM) (ZEISS HR-SEM), Transmission electron microscope 
(TEM)(JEOL/ JEM 2100), EDX (Oxford Inca software) were used to characterize the nano particles. FTIR was used to find the presence of functional group in the nano particle, SEM and TEM analysis was used to find the size, shape, structure and internal morphology of the nano particles and in order to find the elemental composition of nano particle EDX analysis was also performed.

Table 3. Chemical characteristics of ALL and CFL

\begin{tabular}{ccc}
\hline Parameter & ALL & CYL \\
\hline Age & $>10$ & $<5$ \\
\hline $\mathrm{pH}$ & 7.6 & 7.4 \\
\hline Color & 20000 & 14000 \\
\hline $\mathrm{EC}$ & 23.420 & 9.141 \\
\hline $\mathrm{TDS}$ & 26830 & 19020 \\
\hline $\mathrm{COD}$ & 19691 & 22148 \\
\hline $\mathrm{BOD}$ & 24000 & 16000 \\
\hline $\mathrm{Na}$ & 483 & 352 \\
\hline $\mathrm{K}$ & 1657 & 1118 \\
\hline $\mathrm{Cd}$ & $\mathrm{Nil}$ & $\mathrm{Nil}$ \\
\hline $\mathrm{Cr}$ & 0.039 & 0.007 \\
\hline $\mathrm{Cu}$ & $\mathrm{Nil}$ & $\mathrm{Nil}$ \\
\hline $\mathrm{Zn}$ & 0.065 & 0.004 \\
\hline $\mathrm{Fe}$ & $\mathrm{Nil}$ & $\mathrm{Nil}$ \\
\hline $\mathrm{Pb}$ & $\mathrm{Nil}$ & $\mathrm{Nil}$ \\
\hline $\mathrm{No}{ }^{-}$ & 477.500 & 452.100 \\
\hline $\mathrm{Ag}$ & &
\end{tabular}

${ }^{*}$ All in $\mathrm{mg} \mathrm{l}^{-1}$ except $\mathrm{pH}, \mathrm{EC}\left(\mu \mathrm{S} \mathrm{cm}^{-1}\right)$, color (pt.co)

\subsection{Experimental procedure}

Batch studies were carried out to perform the experiments using two different nano particles. The nano particle dose was varied from 0.1 to $0.5 \mathrm{~g} / 50 \mathrm{ml}$. $\mathrm{pH}$ was varied between 2 to 10 and the contact time as 30 to 150 minutes and the hydrogen peroxide concentration as 1 to $5 \mathrm{M}$. The supernatant was filtered using Whattman 42 filter paper and analyzed for the percentage removal of color, BOD and COD. The color, BOD and COD were analyzed by following the standard methods provided in IS: 3025 (2009). The percentage removal was calculated using Eq. (1).

$$
\text { \% removal }=\frac{\mathrm{C}_{\mathrm{i}}-\mathrm{C}_{\mathrm{f}}}{\mathrm{C}_{\mathrm{i}}} \times 100
$$

\section{$\mathrm{C}_{\mathrm{i}}$-Initial concentration $\left(\mathrm{mg} \mathrm{l}^{-1}\right)$ \\ $\mathrm{C}_{\mathrm{f}}$ - Final concentration $\left(\mathrm{mg} \mathrm{l}^{-1}\right)$}

\section{Results and discussion}

\subsection{SEM and EDX Analysis}

The surface structure and elemental composition of SNP and INP were studied using SEM and EDX analysis and presented in Figure 1 . It can be noted from Fig $1 \mathrm{~b}$, the amount of silica content in the raw blast furnace slag was found to be $9.74 \%$. After the extraction of silica from the blast furnace slag the amount of silica present in it was found to be $26.05 \%$ (Fig. 1d). The raw blast furnace slag was spherical in shape whereas the SNP was irregular in shape. The SEM images of INP were found to be grain shaped. The presence of larger particles was mainly due to agglomeration of particles. The surfaces of the nano particle seem to be quite uneven and aggregated in appearance.

\subsection{TEM Studies}

TEM analysis was carried out to examine the microstructure of the nano particle. The TEM images of SNP and INP are presented in the Figure 2(a) and 2(b) respectively. It can be observed from the figure that the particles were irregular in shape. Further, it can be noted that color contrast was observed in INP (Fig. 2b) in which the dark portion indicates the presence of metallic iron and the lighter portion indicates the presence of iron oxide (Yuvakumar et al., 2011). In SNP (Fig. 2a), the particles are irregular in shape.

\subsection{FTIR analysis}

FTIR analysis was carried out to identify the occurrence of functional group present in the sample and the results are presented in Fig. $3 a$ and Fig. $3 b$ for SNP and INP, respectively. It can be noted from Fig. $3 a$, the peak at 455 $\mathrm{cm}^{-1}$ corresponded to $\mathrm{Si}-\mathrm{O}$ rocking vibration (Singho, 2012). The peak at $800 \mathrm{~cm}^{-1}$ was due to the $\mathrm{Si}-\mathrm{O}$ bending vibration. The strong peak observed at $3400 \mathrm{~cm}^{-1}$ indicates the stretching of $\mathrm{O}-\mathrm{H}$ bond which was mainly due to the presence of $\mathrm{H}_{2} \mathrm{O}$ in the sample (Aguiar et al., 2009). Further, it was reported that the SNP have the affinity to absorb water from the atmosphere (Yazdimamaghani et al., 2010) and hence, it can be stated that the obtained SNP were hygroscopic in character. Other than the strong peaks, many medium peaks were also observed which indicates the formation of amorphous phase of $\mathrm{SiO}_{2}$. From the FTIR spectra of INP (Fig. 3b), it can be observed that the peak at $500 \mathrm{~cm}^{-1}$ represents the presence of Iron oxide. The wide band observed in the region between $3200-3400 \mathrm{~cm}^{-1}$ corresponded to the stretching of $-\mathrm{OH}$ bond.

\subsection{Batch experiments}

Batch experiments were conducted to study the influence of various operating parameters such as $\mathrm{pH}$, dosage of nano particles, concentration of hydrogen peroxide and contact time.

\subsubsection{Effect of $p H$}

The effect of $\mathrm{pH}$ on the removal of color, BOD and COD was studied by varying the $\mathrm{pH}$ range from 2 to 10 . The experiments were carried out for both aged leachate (ALL) and also the leachate from the composting yard (CYL) using SNP and INP by keeping the contact time as 30 minutes with the hydrogen peroxide concentration of $1.5 \mathrm{M}$ and nano particle dose of $0.1 \mathrm{~g} / 50 \mathrm{ml}$ and the results are presented in Fig. 4. 


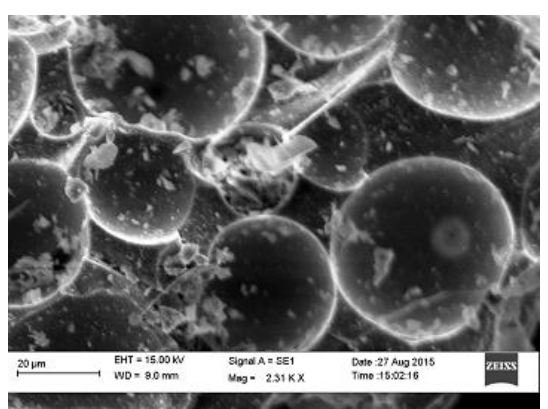

(a)

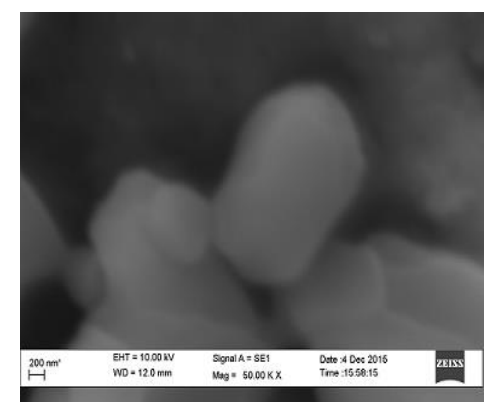

(c)

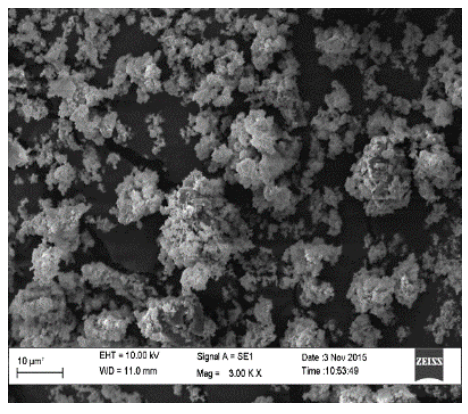

(e)

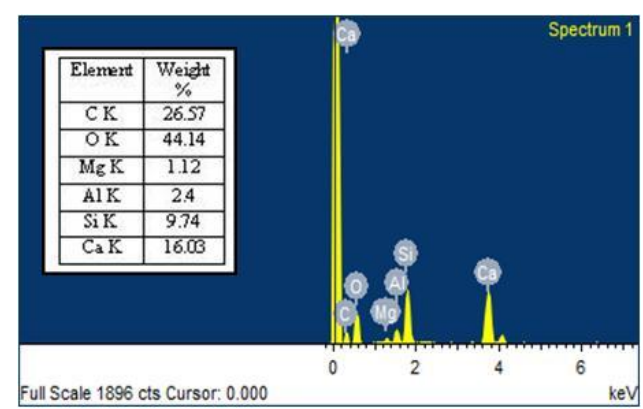

(b)

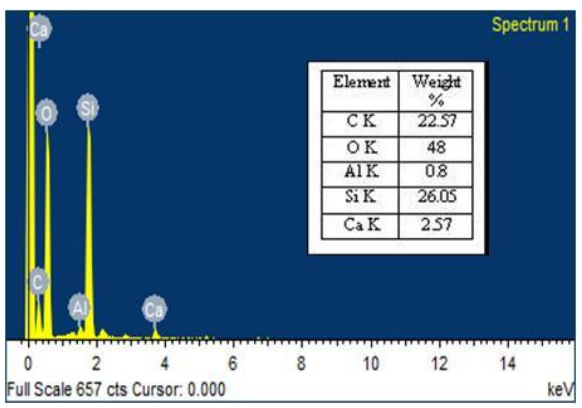

(d)

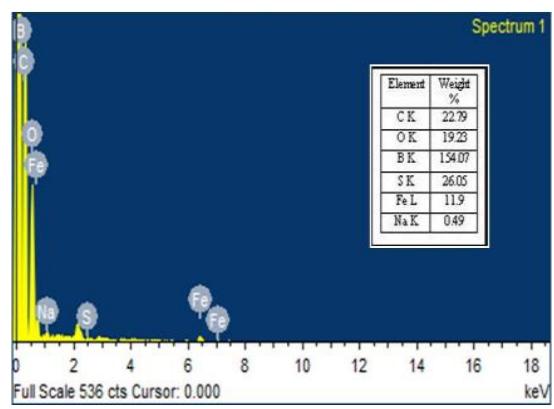

(f)

Figure 1. SEM and EDX of Raw BFS(a,b), SNP(c, d) and INP(e,f)

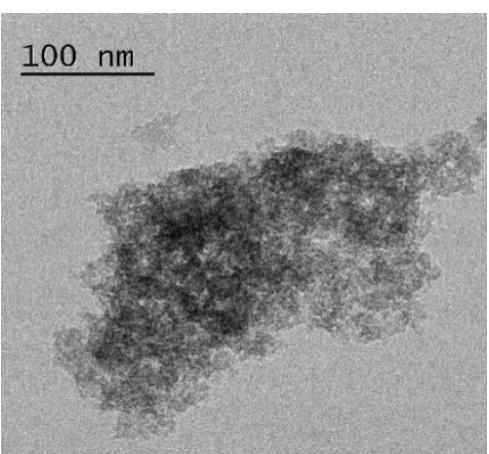

(a)

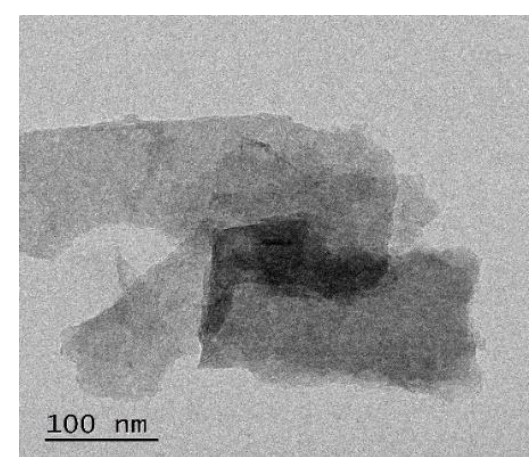

(b)

Figure 2. TEM image of (a) SNP and (b) INP 


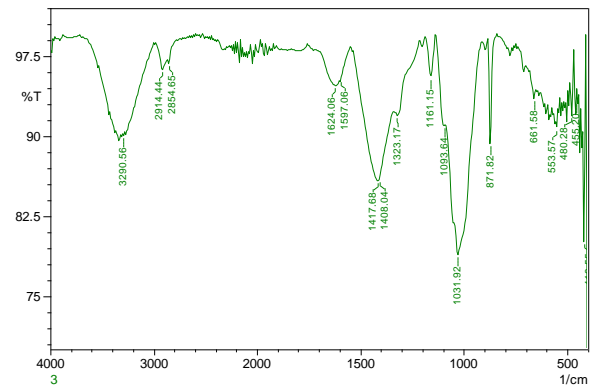

(a)

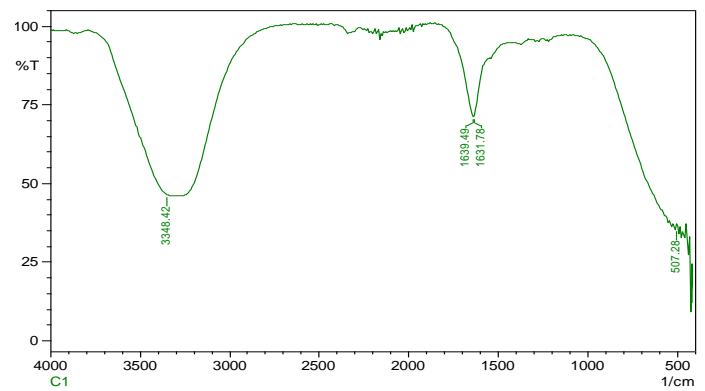

(b)

Figure 3. FTIR image of (a) SNP and (b) INP

It can be noted from the figure that the maximum removal of color, BOD and COD for both ALL and CYL were obtained

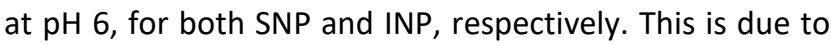
the fact that in alkaline condition, the nanoparticles along with hydroxyl radical lead to the production of hydroxide precipitate (Shu et al., 2007). This precipitate occupied the active sites in the nano particles and prevented the further

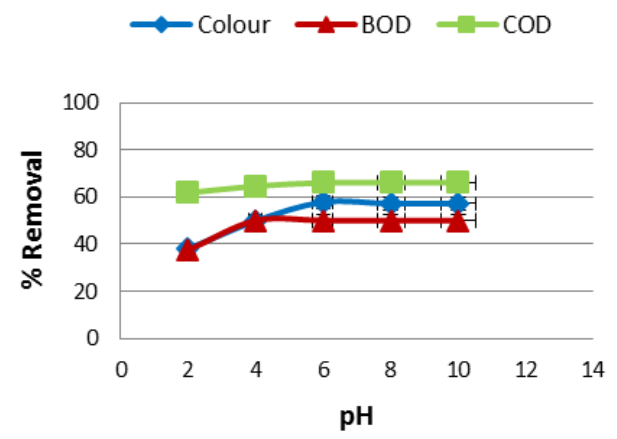

(a)

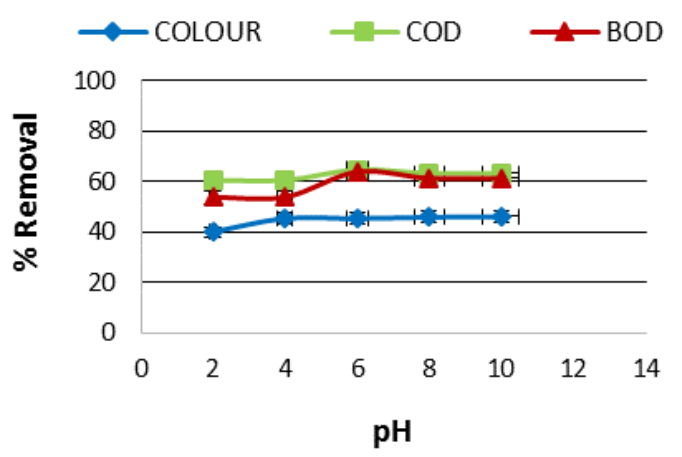

(c)

Figure 4. Effect of $\mathrm{pH}$ on removal of color, BOD and COD

Further, it can be noted that for SNP, the removal efficiency of color, BOD and COD for CYL (Fig. 4b) was found to be $70.37 \%, 62.50 \%$ and $73.09 \%$ respectively and for ALL (Fig. 4a) it was found to be $57.82 \%, 50.16 \%$ and $66.01 \%$ respectively. Similarly for INP application in CYL, the activity. Hence, beyond $\mathrm{pH} 6$ the removal efficiency was found to be constant. The oxidation and reduction potential was more from the $\mathrm{pH} 2$ to 6 and at higher $\mathrm{pH}$ no more oxidation was observed. Thus the nano particles were more effective in acidic $\mathrm{pH}$ than at alkaline $\mathrm{pH}$. The obtained results were consistent with the results reported in literature (Farrokhi et al., 2009; Jashni et al., 2009).

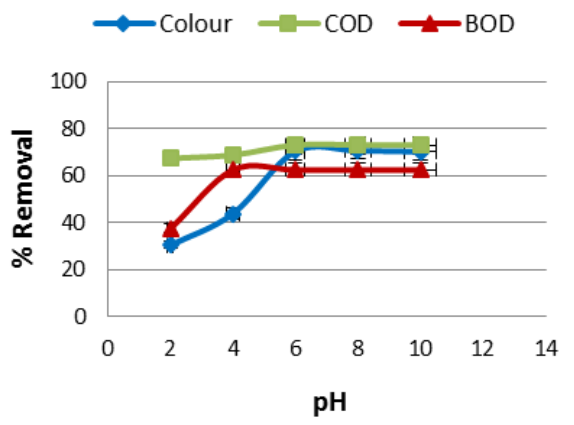

(b)

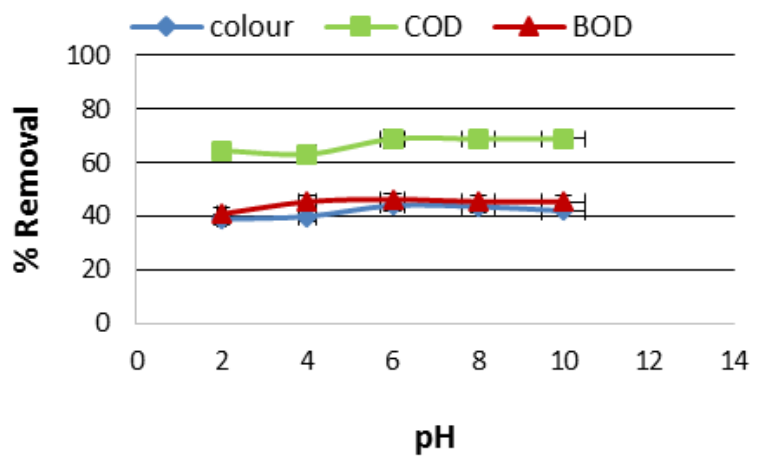

(d)

(a) ALL (SNP), (b)CYL(SNP), (c)ALL(INP) and (d) CYL(INP)

removal efficiency of color, BOD and COD was found to be 49.78\%, 63.75\%, 66.01\% respectively (Fig. 4d) and for ALL it was found to be $59.39 \%, 55.45$, and $77.34 \%$ respectively (Fig. 4c). The difference in removal efficiency was due to 
the presence of large amount of organic compound in CYL than that of ALL.

\subsubsection{Effect of nano particles dosage}

The effect of SNP and INP dosage on the removal efficiency of colour, BOD, COD are presented in the Figure 5. By keeping the other parameters constant $(\mathrm{pH} \mathrm{6}$, contact time 30 minutes and hydrogen peroxide concentration $1.5 \mathrm{M}$ ), the experiments were carried out for $A L L$ and $C Y L$ by varying the SNP dosage from 0.1 to $0.5 \mathrm{~g} / 50 \mathrm{ml}$. The maximum removal efficiency for SNP was observed at the dosage of $0.4 \mathrm{~g} / 50 \mathrm{ml}$. At this dosage the removal efficiency of color, BOD, COD was found to be $50.35 \%, 62.59 \%$, $67.42 \%$ and $72.28 \%, 65.94 \%, 68.81 \%$, for ALL and CYL respectively. Similarly, using INP, the maximum percentage removal was observed at the dosage of $0.3 \mathrm{~g} / 50 \mathrm{ml}$, at which the maximum removal was found to be $54.50 \%$, $54.56 \%$ and $64.73 \%$ for ALL and $56.49 \%, 63.98 \%$ and

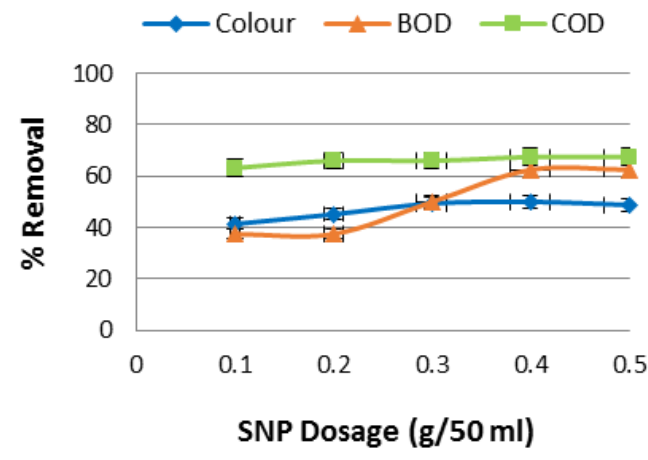

(a)

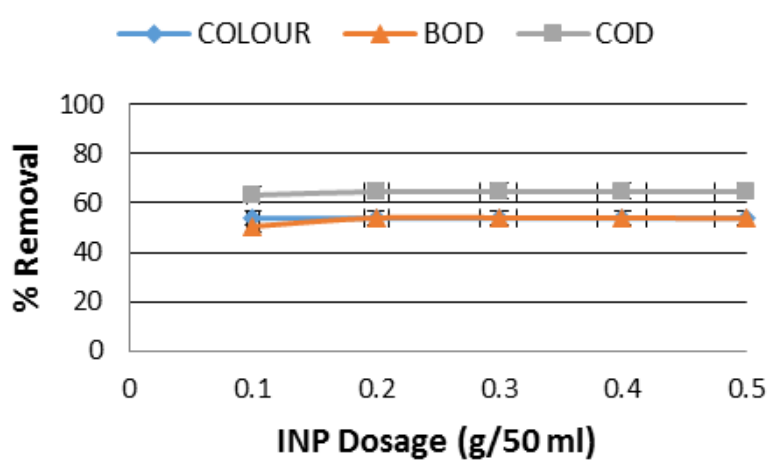

(c)
$68.37 \%$ for CYL respectively. By increasing the active surface area there was more possibility of interaction within nano particle and organic, inorganic substances present in the leachate. Petrisevski et al., (2007) reported that increasing the oxidation and reduction reaction is also the possible reason for the removal efficiency. Further, it can be noted from the figure that the removal efficiency found to be almost constant beyond $0.4 \mathrm{~g} / 50 \mathrm{ml}$ for SNP and $0.3 \mathrm{~g} / 50 \mathrm{ml}$ for INP. This is due to the fact that the excess amount of nano particles causes turbidity and reduces the oxidation potential and interference in leachate treatment (Shu et al., 2010). Shu, (2007) reported similar trend in azo dye removal using nanoparticles and the removal efficiency was found to be $95 \%$. Shao-Feng, (2005) reported that the removal of hexavalent chromium with nano particle was found to be $100 \%$ at $0.4 \mathrm{~g} \mathrm{l}^{-1}$ and the removal was found to be $26 \%$ in $0.1 \mathrm{~g}^{-1}$.

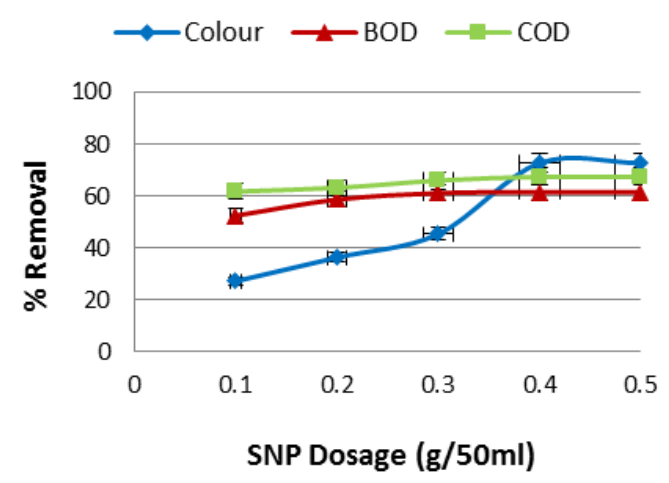

(b)

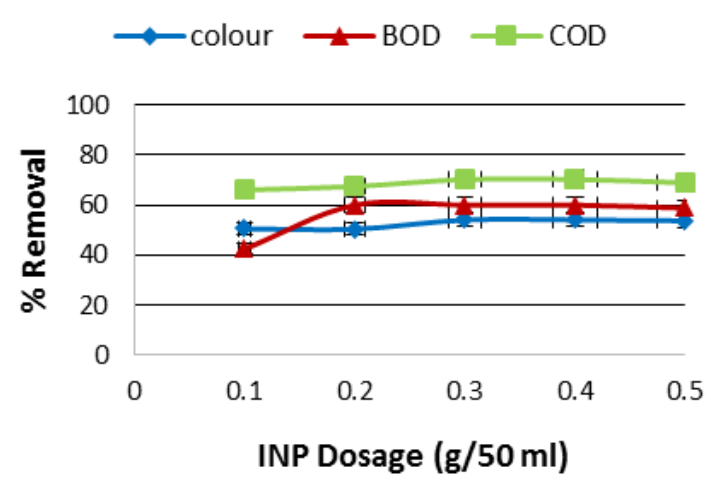

(d)

Figure 5. Effect of nano particle dosage on the removal of Color, BOD and COD (a) ALL(SNP),(b) CYL(SNP), (c) ALL(INP) and (d) CYL(INP)

\subsubsection{Effect of contact time}

The effect of contact time was studied by keeping other parameters as constant, i.e., $\mathrm{pH} 6$, adsorbent dosage $0.4 \&$ $0.3 \mathrm{~g} / 50 \mathrm{ml}$, Hydrogen peroxide $1.5 \mathrm{M}$ and varying the contact time in the range of 30 - 150 minutes (Figure 6). The optimum contact time was found to be 90 minutes at which the maximum removal of color, BOD, COD was achieved for CYL and ALL. The maximum percentage removal of color, BOD,COD was obtained as $67.90 \%$,
75.83\%, $81.95 \%$ and $74.87 \%, 72.41 \%$ and $84.84 \%$ for ALL (Fig. 6a) and CYL (Fig. 6b) respectively, for SNP. It can be noted from the figures that increase in contact time increases the removal efficiency. It signifies that the reaction between the silica nano particle and hydrogen peroxide was almost completed between the reaction time of 30 to 90 minutes. Similar trend was observed for INP, with $\mathrm{pH} 6$, nano particle dosage $0.3 \mathrm{~g} / 50 \mathrm{ml}$, the maximum removal efficiency of ALL (Fig. 6c) and CYL (Fig. 6d) was 
found to be $64.73 \%, 56.36 \%, 67.43 \%$ and $65.05 \%, 55.37 \%$, $68.94 \%$ respectively, at 120 minutes. The obtained results are consistent with the results reported in literature for

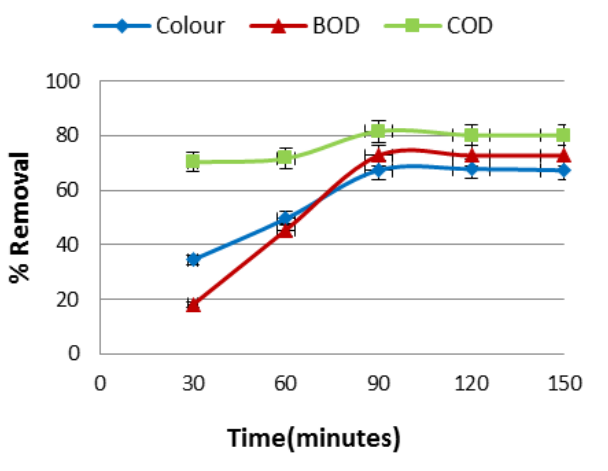

(a)

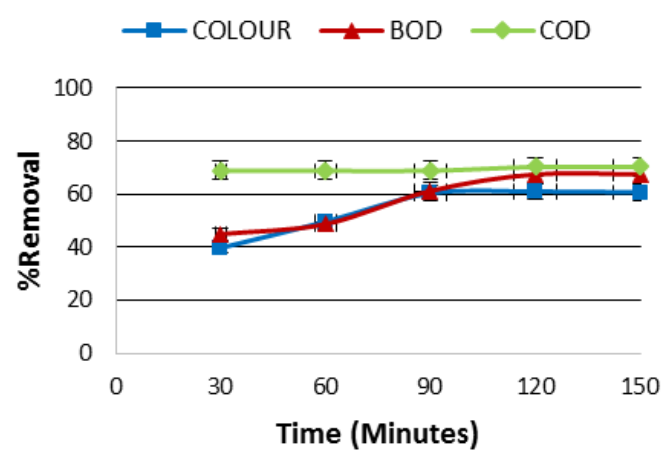

(c) leachate treatment (Farrokhi et al., 2009, Jashni et al., 2008).

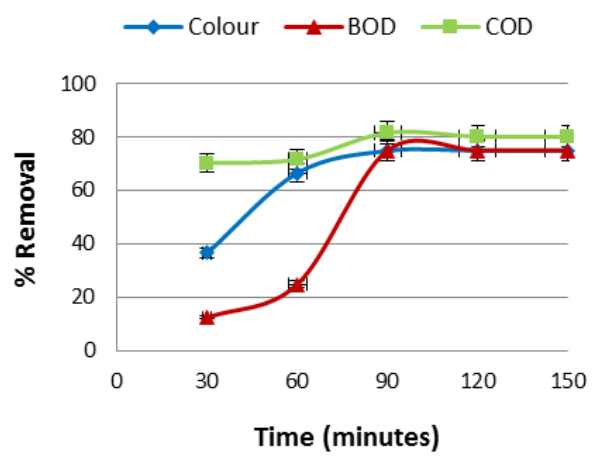

(b)

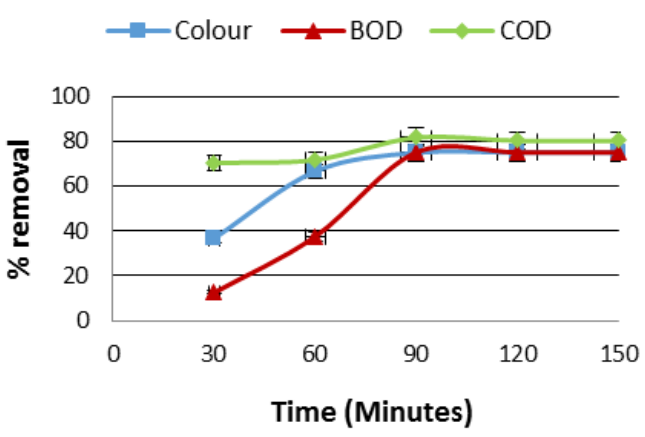

(d)

Figure 6. Effect of contact time on the removal of color, BOD and COD (a)ALL (SNP),(b)CYL(SNP), (c)ALL(INP) and (d) CYL(INP)

\subsubsection{Effect of Hydrogen peroxide concentration}

With optimized $\mathrm{pH}$ as 6 and nano particle dosage as $0.4 \mathrm{~g} / 50 \mathrm{ml}$ and $0.3 \mathrm{~g} / 50 \mathrm{ml}$ (for SNP and INP respectively) and contact time as 90 and 120 minutes (for SNP and INP respectively) the hydrogen peroxide concentration was varied from $1.5 \mathrm{M}$ to $3.5 \mathrm{M}$ and $1 \mathrm{M}$ to $5 \mathrm{M}$ for SNP and INP respectively. The removal efficiency of color, BOD and COD was found to be $77.15 \%, 62.72 \%, 87.15 \%$ and $82.56 \%$, 62.51\%, $77.34 \%$ for ALL (Fig. 7a) and CYL (Fig. 7b) respectively, for SNP. It can be noted from the figure that the maximum removal efficiency was achieved at $3 \mathrm{M}$. Similar trend was observed by using INP and maximum removal efficiency was found to be $57.06 \%, 57.27 \%$, $67.43 \%$ for ALL (Fig. 7c) and 60.36\%, 65.09\%, 67.43\% for CYL (Fig. 7d) respectively, for the Hydrogen peroxide concentration of $4 \mathrm{M}$.

\section{Conclusions}

The potential of SNP synthezed from blast furnace slag, a waste obtained from the foundary unit and INP synthesized using chemicals, for the removal of color, BOD and COD was studied. The effect of $\mathrm{pH}$, contact time, nano particle dosage and hydrogen peroxide concentration were investigated and the optimum condition for maximum removal using SNP was found to be $\mathrm{pH} \mathrm{6,} \mathrm{contact} \mathrm{time} 90$ minutes, nano particle dose $0.4 \mathrm{~g} / 50 \mathrm{~mL}$ and hydrogen peroxide concentration $3 \mathrm{M}$. Similary, for INP it was found to be $\mathrm{pH} \mathrm{6,} \mathrm{contact} \mathrm{time} 120$ minutes, nano particle dosage $0.3 \mathrm{~g} / 50 \mathrm{~mL}$ and hydrogen peroxide concentration $4 \mathrm{M}$. Based on the obtained results, it can be concluded that the removal efficiency using both SNP and INP was comparitively high for CYL than the ALL due to the nature of leachate characteristics. 


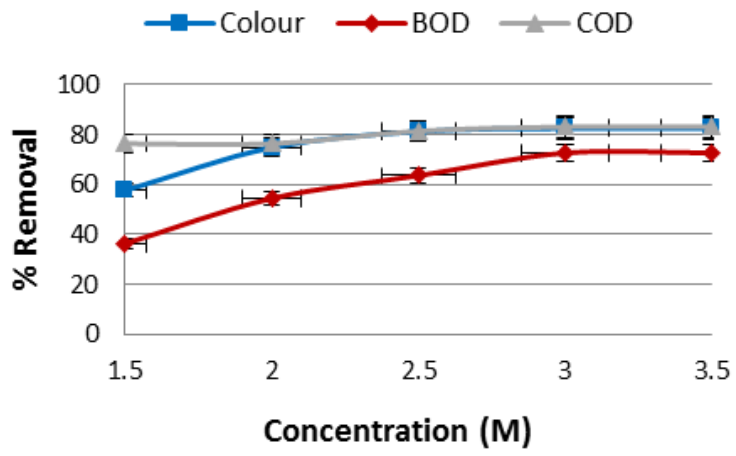

(a)

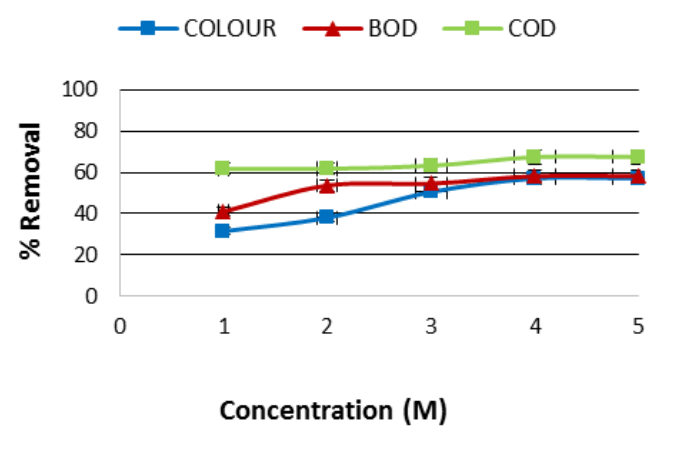

(c)

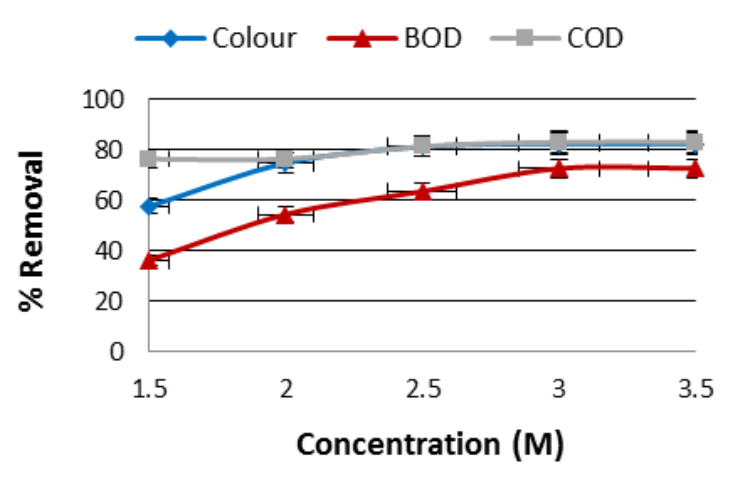

(b)

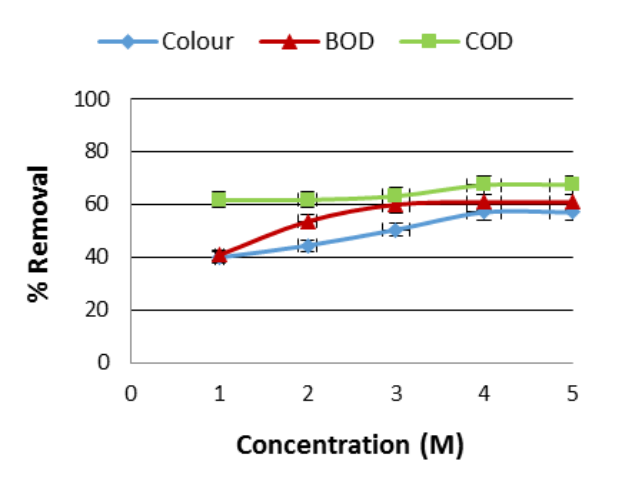

(d)

Figure 7. Effect of hydrogen peroxide on the removal of color, BOD and COD (a )ALL (SNP),(b) CYL(SNP), (c) ALL(INP) and (d) CYL (INP)

\section{Acknowledgement}

The authors would like to thank VIT University for providing Atomic Absorption Spectroscopy (AAS) for analysis of metal concentration and SEM-EDAX facility for morphology and elemental analysis. The authors would also like to thank the CUSAT for providing the facility to carry out TEM analysis.

\section{References}

Aguiar H., Serra J., González P. and León B. (2009), Structural study of sol-gel silicate glasses by IR and raman spectroscopy, Journal of Non-Crystalline Solids, 355, 475-480.

Allabaksh B.M., Kumar Mandal B., Mohan Kumar B., Siva Kumar K.K and Pamanji Sreedhara Reddy (2010), Preparation of Stable Zero Valent Iron Nanoparticles using Different Chelating Agents, Journal of Chemical and Pharmaceutical Research, 2(5), 67-74.

APHA 2012. Standard Methods for Examination of Water and Wastewater, 22 ${ }^{\text {nd }}$ Edition, American Public Health Association, Washington, DC.

Baccini P., Henseler G., Figi R. and Belevi (1987), Water and element balances of municipal solid waste landfills, Waste Management Research, 5, 483-499.

Bailey S.E., Olin T., Bricka R.M. and Adrian D.A. (1999), A review of potentially low-cost sorbents for heavy metals, Water Resource, 33, 2469-2479.

Dukkanci M., Gunduz G., Yilmaz Y., Yaman S., Prikhod'ko I. and Stolyarova R. (2010), Characterization and catalytic activity of
CuFeZSM- 5 catalysts for oxidative degradation of Rhodamine $6 \mathrm{G}$ in aqueous solutions, Applied Catalysis-B, 95, 270-278.

Esfahani K.Z., Samadi M., Naddafi K., Afkhami A. and Rahmani A. (2012), Application of Iron nano particles in Landfill leachate treatment (Case study: Hamadan landfill leachate, Iranian Journal of Environmental Health, Science and Engineering, 9(36), DOI 10.1186/1735-2746-9-36.

Farrokhi M., Kouti M., Mousavi G.R. and Takdastan A. (2009), The Study on Biodegradability Enhancement of Landfill Leachate by Fenton Oxidation, Iranian Journal of Health and Environment, 2(2), 114-123.

IS: 3025 (2009), Methods of sampling and test (Physical and chemical) for water and waste water. Bureau of Indian Standards, New Delhi.

JaeKim S., Gyu Seo S. and Chul Jung S. (2010), Preparation of high purity nano silica particles from blast-furnace slag, Korean Journal of Chemical Engineering, 27(6), 1901-1905.

Jashni A.K. and Omranimanesh R. (2008), Study on degradability of landfill leachate by Fenton oxidation, In: proceeding of 10th conference environmental health, Tehran.

Lema J.M., Mendez R. and Blazquez R. (1988), Characteristics of landfill leachates and alternatives for their treatment: a review, Water Air Soil Pollution, 40, 223-250.

Lopez A., Pagano M., Volpe A. and Claudio A. (2004), Fenton's pretreatment of mature landfill leachate, Chemosphere, 54(7), 1005-1010. 
Luo W., Zhu L.H., Wang N., Tang H.Q., Cao M.J. and She Y.B. (2010), Efficient removal of organic pollutants with magnetic nano scale $\mathrm{BiFeO}_{3}$ as a reusable heterogeneous Fenton-like catalyst, Environmental Science and Technology, 44, 1786-1791.

Mor S., Ravindra K., Visscher A.D., Dahiya R.P. and Chandra A. (2006), Municipal solid waste characterization and its assessment for potential methane generation: a case study, Journal of Science of the Total Environment, 371, 1-10.

Patra A.K., Dutta A. and Bhaumik A. (2013), Mesoporous coreshell Fenton Nano catalyst: Amild, operationally simple approach to the synthesis of adipic acid, Chemistry- $A$ European Journal, 19(37), 12388-12395.

Petrisevski B., Shamma S., Schippers J.C. and Shordt K. (2007), Arsenic in drinking water. IRC International water and sanitation centre.

Petruzzelli D., Boghetich G., Petrella M., Dellerba A., Labbate P., Sanarica S. and Miraglia M. (2007), Pre-treatment of industrial landfill leachate by Fenton's Oxidation, Global Nest Journal, 9(1), 51-56.

Ramesh N., Meenambal T. and Murugan K. (2009), Quantification, Characterization and Leachate Analysis of the Municipal Solid Waste from Erode Municipality, Tamilnadu, India, Nature Environment and Pollution Technology, 8(1), 21-28.

Sarvako M. (2007), Physicochemical performance of leachate treatment, A case study for separation technique, Journal of applied sciences, 7(23), 3827-3830.

Shao Feng N., Yong L., Xin- Hua X. and Zang -Hau L. (2005), Removal of Hexavalent chromium ion from aqueous solution by iron nano particle , J Zhejiang University Science, 6(10), 1022-1027.

Sharholy M., Ahmad K., Mahmood G. and Trivedi R.C. (2005), Analysis of municipal solid waste management systems in Delhi - a review, In: Book of Proceedings for the second International Congress of Chemistry and Environment, Indore, India.

Shu H.Y., Chang M.C., Yu H.H. and Chen W.H. (2007), Reduction of an azo dye acid black 24 solution using synthesized nanoscale zero valent iron particles, Journal of Colloid Interface Science, 314, 89-97.

Siddiqui T.Z., Siddiqui F.Z. and Khan E. (2006), Sustainable development through integrated municipal solid waste management (MSWM) approach - a case study of Aligarh District, In: Proceedings of National Conference of Advanced in Mechanical Engineering, Jamia Millialslamia, New Delhi, India, 1168-1175.

Singho N.D. and Johan M.R. (2012), Complex impedance spectroscopy study of silica nanoparticles via sol-gel method, International Journal of Electrochemical Science, 7, 5604-5615.

Tanapon P., Navid S., Kevin S., Robert D. and Gregory V. (2007), Aggregation and Sedimentation of Aqueous Nanoscale Zerovalent Iron Dispersions, Environmental Science and Technology, 41(1), 284-290.

Tian S.H., Tu Y.T., Chen D.S., Chen X.Y. and Xiong (2011), Degradation of acid orange II at Neutral pH using $\mathrm{Fe}_{2}\left(\mathrm{MoO}_{4}\right)_{3}$ as a heterogeneous Fenton-like catalyst, Chemical Engineering Journal, 169(1-3), 31-37.

$\mathrm{Xu}$ L.J. and Wang J.L. (2012), Magnetic nanoscale $\mathrm{Fe}_{3} \mathrm{O}_{4} / \mathrm{CeO}_{2}$ composite as an efficient Fenton-like heterogeneous catalyst for degradation of 4-chlorophenol, Environmental Science and Technology, 46, 10145-10153.

Yang D. and Engelhard J. (2006), Treatment of landfill by the Fenton process, Water Research, 40(20), 3683-3694.

Yazdimamaghani M., Pourvala T., Motamedi E., Fathi B., Vashaee D. and Tayebi L. (2013), Synthesis and characterization of encapsulated nano silica particles with an acrylic copolymer by in sit emulsion polymerization using thermo responsive nonionic surfactant, Materials, 6(9), 3727-3741.

Yuvakumar R., Elango V., Rajendran V. and Kannan V. (2011), Preparation And Characterization Of Zero Valent Iron Nanoparticles, Digest Journal of Nanomaterials and Biostructures, 6(4), 1771-1776.

Zhang H., Choi H. and Huangb C.P. (2007), Treatment of landfill leachate by Fenton's reagent in a continuous stirred tank reactor, Journal of Hazardous Materials, 136(3), 618-623. 